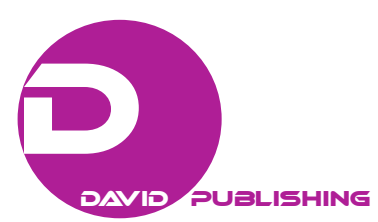

\title{
Empirical Validation of Key-Factors of Connected Remote Services
}

\author{
Adam-Alexander Manowicz \\ University of Latvia, Riga, Latvia
}

\begin{abstract}
Based on an exploration of key-factors of connected remote services (CRS) by means of a qualitative study among German automotive customers, this study operationalizes the phenomenon. The definition of CRS as service innovation captures the special particularity of connectedness as attribute, providing simultaneous connectivity of customers to a service object (e.g. car), and a service provider (e.g. dealer and car manufacturer). The measurement model is conceptualized as a second-order formative construct defining the five key-factors: convenience, connectedness, comfort, safety, and reliability as first-order reflective constructs as identified in the prior qualitative study. The scale validation was undertaken at the first- and second-order levels. The result confirms the five distinct first-order measurement models. At the second-order level, a multiple indicators and multiple causes (MIMIC) model was employed to assess the validity of the formative measurement model. The operationalization confirms the distinctness of the five CRS key-factors. Further, the results suggest that four of five key-factors significantly contribute to the overarching construct of connected remote services, with safety and connectedness being the most important contributors and comfort to be shown as not significant. The confirmed concept of CRS will provide future research with a basis to explore different impacts of CRS use, e.g. in the context of technology acceptance and intentional customer behavior.
\end{abstract}

Keywords: automotive after-sales, connected remote services, formative measurement, MIMIC model, means-end chain analysis

\section{Introduction}

One general trend in the automotive industry is that the isolated focus on car-sales is replaced by a wider view, considering the initial car sale more of an enabler for beginning relationships with customers. Hence, car sales become the starting point for relationship management based on additional services expanding the traditional aftersales business, which today mainly consists of maintenance and repair services (Confente \& Russo, 2016, p. 59). At the same time, the need for service innovation has never been greater to ensure and expand market share and profits. One challenge to systematic service innovation is to combine technology, business, social, and customer needs in the creation process (Spohrer \& Maglio, 2008, p. 238). However, there is little research and knowledge on developing and designing new services. While customers are more and more competent in articulating their needs, and expressing their demands, the success of service innovation

Adam-Alexander Manowicz, Dipl. Ing., Faculty of Economics and Business Management, University of Latvia, Riga, Latvia.

Correspondence concerning this article should be addressed to Adam-Alexander Manowicz, Faculty of Economics and Business Management, University of Latvia, Aspazijas bulv.5, LV1050, Riga, Latvia. 
becomes more and more dependent on the use and integration of information technology and digitization of information processes into the service delivery system (Bouwman, Vos, \& Haaker, 2008, p. 3). This research aims to investigate the concept of connected remote service in the automotive after-sales business, using the multiple indicators, multiple causes model to operationalize formative variables (Lee, Cadogan, \& Chamberlain 2013, p. 3). In recent years, scholars started recommending MIMIC model specification for formative measurement in SEM (Henseler, 2017, p. 183), especially if it is necessary to combine reflective and formative measurement (Vinzi, Trinchera, \& Amato, 2010, p. 49). As per Diamantopoulos (2011, p. 349), “a two-construct SEM comprised of one formatively measured latent variable that impacts on a single reflectively measured latent variable is directly equivalent to a single-construct model comprising the same set of formative indicators (i.e., a MIMIC model)". The main finding of this paper is the evaluation of the MIMIC model, describing the interrelationship between intended CRS key-factors and the overall CRS concept. It empirically evaluates the results from the conceptualization of CRS based on the prior conducted explorative qualitative research. These findings contribute to the development of a comprehensive research model to examine the impact of CRS on technology acceptance and behavioral intentions.

\section{Literature Review}

According to Kotler and Bloom (1984), a service is: "any act or performance that one party can offer to another that is essentially intangible and does not result in the ownership of anything. Its production may or may not be tied to a physical product." An indispensable characteristic of service is the necessity of the integration of an external factor (e.g. customer) into the process of service delivery which consists in the introduction of a service object by the consumer into the creation and delivery process of the service (Hilke, Trippen, \& Peiner, 1989, p. 12). The novelty of a service innovation can consist of a new service, a new service portfolio and/or a new service process that individually or in combination defines a new way of creating value for the customer (Den Hertog, Van der Aa, \& De Jong, 2010, p. 494). Further, the authors concretely categorize possible dimensions and describe service innovation as "a new service experience or service solution that consists of one or several of the following dimensions: new service concept, new customer interaction, new value system/business partners, new revenue model, new organizational or technological service delivery system." Applying these criteria towards CRS it can be stated that it introduces a new way of customer interaction as well as new business partners, revenue models, and technology based delivery system. Therefore, the definition of Den Hertog et al. (2010) shall be the foundation for the further process of this research. Another important aspect of service innovation is described by Toivonen and Tuominen (2009, p. 893), who combine the mutual dependency of benefit creation. The authors state that "A service innovation [...] provides benefit to the organization that has developed it; the benefit usually derives from the added value that the renewal provides the customers." Inferentially, an important target of the introduction of service innovation is the creation of customer benefits.

As a subset of mobile services, recently remote services as an additional type of services has developed, describing a separate kind that can be delimited from traditional services because a technological interdependence occurs within the delivery process of the service. The definition of service innovation in conjunction with the definitions of remote services of Wünderlich, Schumann, Wangenheim, and Holzmüller (2007, p. 7) and connected services of Hiraoka (2009, p. 16) are the foundation for the proposed definition of connected remote services by the author of this paper: 
Connected remote services are innovative mobile remote services that enable customers to interact with the service object as well as the service provider by using mobile infrastructure independently of the spatial distance. This infrastructure enables the bidirectional exchange of information and the control of the service object via data channels.

CRS require several control elements. Information and communication technology (ICT) enables the service provider to access the service object as well as the customer's mobile device. The customer needs access to ICT that makes it possible to query data and to control and modify the service object. The service object must be able to feed the system via ICT with data of its own status. This enables the customer and the service provider to access the service object to monitor, to perform diagnostics, and to control it (Wünderlich et al., 2007, p. 13). Figure 1 describes the information and communication flows within the system architecture.

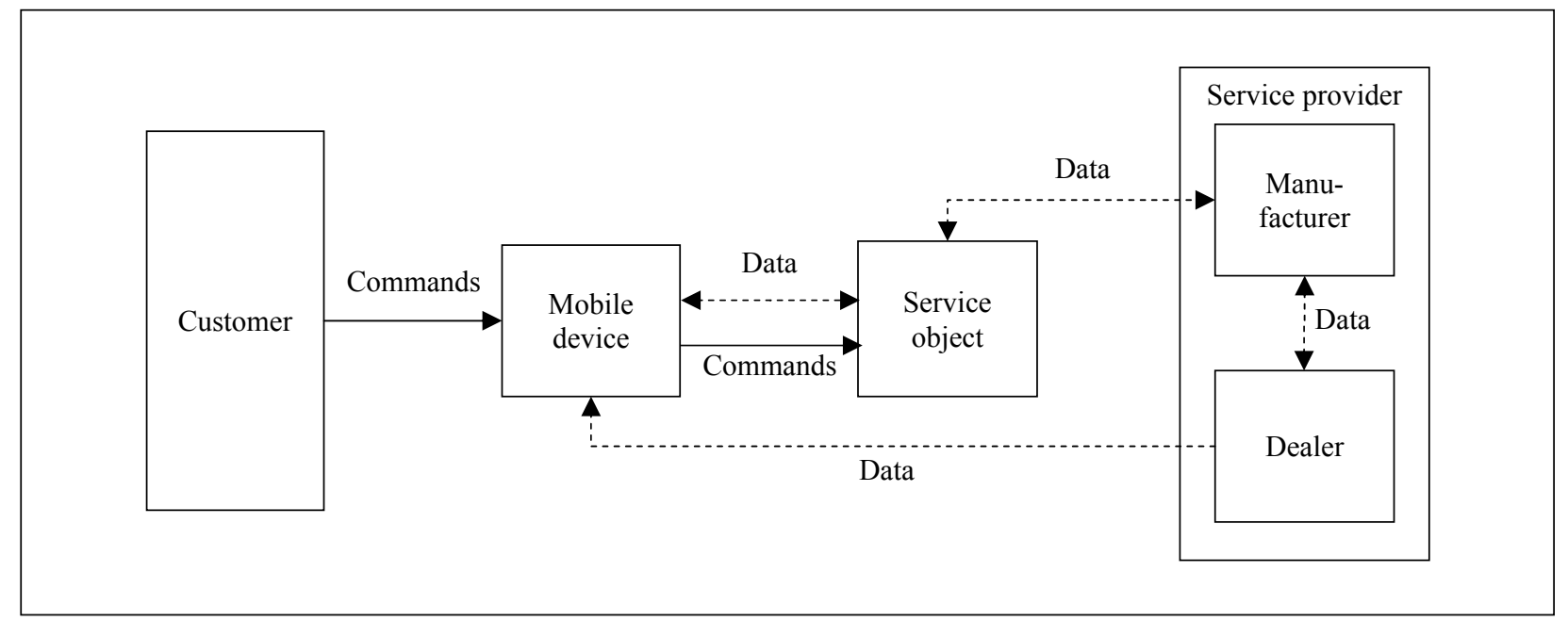

Figure 1. Schematic system-architecture overview of CRS (Author's construction, extended from Wünderlich et al. 2007, p. 13).

\section{Research Methods}

\section{Exploration of Connected Remote Services for the Development of CRS MIMIC Research Model}

The conceptualization of CRS is based on an explorative, qualitative research approach using the method of means-end chain (MEC) analysis. The means-end theory posits that linkages between product attributes consequences produced through consumption, and personal values of consumers underlie their decision-making processes (Gutman, 1991, p. 143). Means are products or services, and ends are personal values considered important to consumers. Transferred to the context of this research, the mechanism of a means-end chain makes it possible to track back perceived consequences towards certain attributes or functions of a product or service (Gutman, 1982, pp. 60-62). Functions of CRS correspond to attributes that lead to attribute-specific consequences, which again lead to relevant values from the customers' perspective. The consequences, located in between attributes and values are of special interest for the identification of key-factors of CRS.

For the survey, conducted during the period of April and May 2017 in Germany, customers of four different brands, were addressed while waiting at the service counter or in the waiting lounge of the dealership. As a prerequisite, the participants should have owned and used a version of CRS in the past six months. The participants are also referred to as users of CRS. The sample size for the written surveys in person consists of 
18 participants. The identified consequences convenience, connectedness, and safety showed the highest numbers of connections and thus substantially determine the construct of connected remote services. The consequences comfort and reliability show lower levels of connections but still on a significant level and are also considered as key-factors for the further process of research. In summary, the explored concept of CRS consists of five key-factors, namely convenience, connectedness, comfort, safety, and reliability. Next, the identified key-factors are classified.

Berry, Seiders, and Grewal (2002), define service convenience as the customers' "time and effort perceptions $[\ldots]$ using a service", considering the specific context of necessary activities that customers carry out while using a service or performing a specific task. In the context of mobile services, Lin and Lu (2015) reveal that mobile convenience directly and positively influences customer value and user satisfaction, because users may use a mobile phone to gather information and accomplish transactions at any time or place and obtain value based on convenience derived from the effective and timely transmission of information. The key-factor convenience is therefore defined as follows: "Convenience describes the degree of simplification and increased promptness a user experiences by use of CRS."

Wamba and Akter (2016) use the term perceived connectivity describing it as the ability of a technology to link people to people or other objects. The second aspect of simultaneous connectedness towards a dealer is reflected in the definition developed by the author of this paper: Connectedness describes the degree a customer feels connected to a specific service object in terms of receiving or query information and sending commands to the service object and simultaneous connectedness towards the dealer.

In the automotive context, Hess $(1924$, p. 1) defines comfort "as the transportation of an automobile passenger in so easy manner that the trip will be a pleasure and not a hardship." Comfort can be perceived both positive and negative. In the negative case, the term discomfort is used (Engeln \& Vratil, 2008, p. 270). It is assumed that perceived increase of comfort leads to an increase of system acceptance (Arndt, 2011). In this work comfort is defined as: The degree the customer perceives physical relaxation (increased comfort) and the degree of stress avoidance (decreased discomfort) while driving the vehicle.

The key-factor safety covers the aspect that the use of CRS increases the customer's perception of feeling secure. Within the context of automotive transport, Joewono and Kubota (2006, p. 87) describe safety as "the actual degree of safety from accidents and the feeling of security resulting from that". It comprises the aspects of safety from accidents, the presence of help, the avoidance of hazards as well as active safeguarding. Hence, in this paper safety is defined as: The subjective feeling of minimizing the individual risk of harming their physical integrity or to increase the probability to ensure their physical integrity.

According to Bracke and Haller (2011), reliability is defined as the degree of increase of sustainability, e.g. by the avoidance of repair efforts by enhanced possibilities of monitoring the condition of the service object. The analysis of the mentions related to reliability in the conducted survey, showed that it was often used relating to the increased reliability of the vehicle itself. The key-factor of reliability is therefore defined as follows: Reliability describes the degree of availability of the service object a user experiences by use of CRS. At the consequence level, perceived often was connected to trust.

The empirical evaluation of the CRS key-factors requires the usage of a multiple indicators and multiple causes (MIMIC) model to identify the model due to the fact that a formative measurement model is naturally not identified (Diamantopoulos \& Winklhofer, 2001). To empirically test the qualitative results from the exploration of CRS, the MIMIC model as shown in Figure 2 is designed as follows: (1) dependent variable is 
connected remote services (CRS); and (2) CRS key-factors form the independent variables convenience (COV), connectedness (CON), comfort (CFT), safety (STY), and reliability (REL).

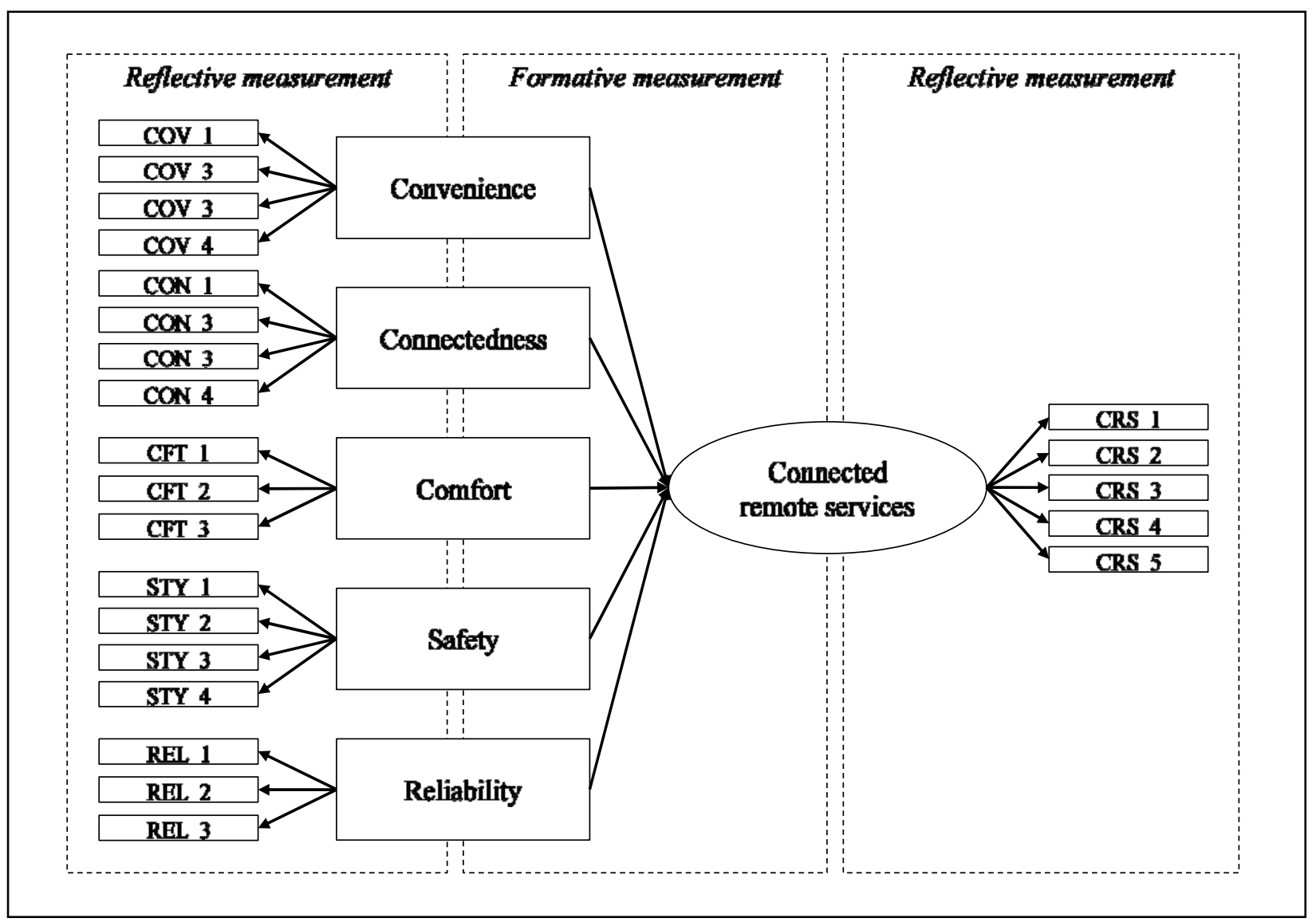

Figure 2. Connected remote services MIMIC model (Authors' illustration).

\section{Research Design and Pre-test}

A two-phase pre-test was conducted to assess validity of the indicators and to ensure that the wording of the questionnaire was clear. In the first step, an item-sort task among 11 selected CRS users was performed to assess the indicators addressed to the five CRS key-factors according to Anderson and Gerbing (1991). Based on the results, three out of 19 indicators were reformulated and improved regarding clearness. One of four indicators from the key-factor comfort was deleted from the questionnaire, because it didn't unambiguously load on one key-factor. In the second step, the complete questionnaire was pre-tested in an online-survey setting. Thirty-four questionnaires were completed by the intended target group of active CRS users. Results showed that the developed questionnaire and survey design is suitable regarding the research targets.

The target population of this study were customers, required to be active CRS users. Data were collected through an online survey, conducted between October 1st and October 13th, 2017. The survey was addressed towards customers from six German car brands, naming the scientific context of the research. Participants were instructed to answer all latent variables on a five-point Likert scale $(1=$ "strongly disagree", $5=$ "strongly agree"). 


\section{Research Results}

In total 701 responses were gained. From this sample, 266 questionnaires were defused from the population because the necessary requirement of active CRS use was not fulfilled, captured by filter-questions. After further proceeded data-cleaning of invalid responses, 331 samples were used for data analysis. Descriptive statistics were analyzed using SPSS 24.0.

The demographic data included information on gender, age, model year, CRS application used, frequency of use and annual mileage. Gender split of the sample was 197 males (59.5\%) and 134 females (40.5\%). In terms of CRS application used, the breakdown was 24.5\% Audi Connect, 23.6 BMW Connected Drive, 21.5\% Mercedes Me, 16.6\% Volkswagen Car-Net, 7.3\% Opel OnStar, and 6.7\% Skoda Connect, indicating a largely even distribution. Respondents were divided into four levels of usage: seldom (41.4\%), regularly (45.3\%), and often $(13.3 \%)$, whereas users that stated to never use CRS were excluded from evaluation. Data analysis included the determination of descriptive statistics, frequency distribution analysis as well as the assessment of reliability and validity. Structural Equation Modeling (SEM) was applied, using the software Smart-PLS 3.2.7. The Partial-Least-Squares (PLS) approach is particularly suitable for the consideration of both, reflective and formative measurement in one model.

For the analysis of the CRS structure, the measurement model is specified as MIMIC model, combining reflective and formative measurement. The five key-factors of CRS are operationalized using reflective indicators. Simultaneously, the five key-factors define the CRS construct, using a formative approach of measurement. In the MIMIC measurement approach, it is necessary to specify a reflective measurement of the CRS construct. For this purpose, five indicators capture the phenomenon globally.

To verify the measurement items, an Exploratory Factor Analysis (EFA) was performed. The five-factor model initially fits the data with total variance explained at $58.8 \%$, which confirms an appropriate level of explanatory power. Test on Bartlett's sphericity neglects the hypothesis that the variables in the model are uncorrelated $(\rho=0.000)$. The Kaiser-Meyer-Olkin (KMO) criterion rates the adequacy of the sample size for model assessment. The value of 0.908 confirms that the number of responses $(n=331)$ is sufficient. The indicator pool initially contained 18 indictors addressed towards five key-factors. The factor analysis confirms that the factors convenience, connectedness, comfort, safety, and reliability represent independent constructs. Each key-factor of the CRS construct displays good levels of reliability. Indicator loadings are throughout above 0.7 . Test of corrected-item-total correlations (CITC) underpins the reliability of the measurement, since all values are above the threshold of 0.5 . Significance is achieved by $t$-values clearly above 1.96 (two-tailed). Values of Cronbach's $\alpha$ are above the threshold as per Nunally (1978, p. 245), who requires its value should be equal to or exceed 0.7. Average variance extracted (AVE) is sufficient for all factors as well as composite reliability (CR). Results are summarized in Table 1.

Analysis of discriminant validity is conducted under use of the Fornell-Larcker criterion. According to this, discriminant validity is present, if the AVE of a factor is higher than the squared correlation of this construct with another construct. Diagonal elements presented the square roots of the average variance extracted. As shown in Table 2, all five factors are distinct from each other.

The evaluation of the reflective measured connected remote services overall concept as a prerequisite for the holistic analysis confirms the one-dimensionality of the phantom variable. Test of CITC, shows that all indicators are well above the threshold, confirming the reliability of the measurement. On the factor level, 
values for $\mathrm{CA}, \mathrm{AVE}$, and $\mathrm{CR}$ also exceed the requirements. Table 3 summarizes the results.

Table 1

Measurement Validation of Key-Factors of Connected Remote Services

\begin{tabular}{|c|c|c|c|c|c|c|}
\hline Description & Loading & CITC & $t$-value & Cronb. $\alpha$ & CR & AVE \\
\hline Convenience & & & & 0.853 & 0.900 & 0.693 \\
\hline COV_1 & 0.825 & 0.683 & 38.135 & & & \\
\hline COV_2 & 0.841 & 0.707 & 44.462 & & & \\
\hline COV_3 & 0.842 & 0.702 & 49.402 & & & \\
\hline COV_4 & 0.822 & 0.679 & 38.526 & & & \\
\hline Connectedness & & & & 0.813 & 0.877 & 0.640 \\
\hline CON_1 & 0.840 & 0.695 & 36.707 & & & \\
\hline CON_2 & 0.809 & 0.656 & 31.777 & & & \\
\hline CON_3 & 0.774 & 0.616 & 26.289 & & & \\
\hline CON_4 & 0.777 & 0.566 & 33.566 & & & \\
\hline Comfort & & & & 0.800 & 0.882 & 0.714 \\
\hline CFT_1 & 0.848 & 0.655 & 41.572 & & & \\
\hline CFT_2 & 0.859 & 0.660 & 43.837 & & & \\
\hline CFT_3 & 0.828 & 0.617 & 33.743 & & & \\
\hline Safety & & & & 0.793 & 0.865 & 0.616 \\
\hline STY_1 & 0.733 & 0.553 & 22.223 & & & \\
\hline STY_2 & 0.805 & 0.626 & 34.900 & & & \\
\hline STY_3 & 0.795 & 0.628 & 28.754 & & & \\
\hline STY_4 & 0.804 & 0.602 & 36.705 & & & \\
\hline Reliability & & & & 0.806 & 0.886 & 0.721 \\
\hline REL_1 & 0.827 & 0.628 & 38.867 & & & \\
\hline REL_2 & 0.841 & 0.636 & 46.517 & & & \\
\hline REL_3 & 0.878 & 0.697 & 63.490 & & & \\
\hline
\end{tabular}

Table 2

Evaluation of Discriminant Validity of Key-Factors of Connected Remote Services

\begin{tabular}{llllll}
\hline CRS key-factor & Convenience & Connectedness & Comfort & Safety & Reliability \\
\hline Convenience & 0.833 & & & & \\
Connectedness & 0.572 & 0.800 & & & \\
Comfort & 0.455 & 0.435 & 0.845 & & \\
Safety & 0.451 & 0.413 & 0.397 & 0.785 & 0.849 \\
Reliability & 0.530 & 0.441 & 0.401 & 0.529 & \\
\hline
\end{tabular}

Table 3

Measurement Validation of Connected Remote Services Overall Construct

\begin{tabular}{|c|c|c|c|c|c|c|}
\hline Description & Loading & CITC & $t$-value & Cronb. $\alpha$ & $\mathrm{CR}$ & AVE \\
\hline \multicolumn{4}{|c|}{ CRS (phantom variable) } & 0.819 & 0.874 & 0.580 \\
\hline CRS_1 & 0.752 & 0.604 & 27.254 & & & \\
\hline CRS_2 & 0.753 & 0.589 & 20.377 & & & \\
\hline CRS_3 & 0.768 & 0.615 & 28.555 & & & \\
\hline CRS_4 & 0.745 & 0.593 & 22.043 & & & \\
\hline CRS_5 & 0.790 & 0.650 & 30.063 & & & \\
\hline
\end{tabular}


Within the evaluation of the formative part of the model, first the VIF values are considered. The achieved values (all VIF values $\leq 3.3$ ) confirm the absence of multicollinearity. Analysis of the path coefficients $(\lambda)$ shows that four out of five values clearly exceed the threshold of 0.1 . Only comfort $\left(\lambda_{3}=0.043\right)$ falls below this threshold. This is also reflected by a low effect size for comfort $\left(f^{2}=0.003\right)$. Nevertheless, the construct is kept in the model, because based on the other criteria, the reliability of the measurement can still be assumed. Results of the $t$-value (two-tailed) evaluation shows that comfort fails the threshold, whereas the other four factors all show $t$-values clearly above the threshold for the $5 \%$ significance level of $t \geq 1.96$. Summarizing, safety shows the highest contribution on CRS, followed by connectedness, convenience, reliability, and comfort. $\mathrm{R}^{2}$ is 0.588 , meaning that $59 \%$ of the variance of the CRS concept can be explained by this model. The Stone-Geisser criterion $\left(Q^{2}=0.317\right)$ is clearly above the threshold of Nitzl $(2010$, p. 37) indicating appropriate predictive relevance. Results of the evaluation of the MIMIC model are displayed in Table 4. Figure 3 graphically depicts the results of the evaluation of the CRS MIMIC model.

Table 4

Evaluation of Connected Remote Services MIMIC Model

\begin{tabular}{llllllll}
\hline Factor & Path coeff. & VIF & Effect size & $t$-value & $p$-value & $\mathrm{R}^{2}$ & $\mathrm{Q}^{2}$ \\
\hline Convenience & 0.227 & 1.836 & 0.068 & 3.369 & 0.001 & & \\
Connectedness & 0.250 & 1.640 & 0.092 & 4.325 & 0.000 & & 0.317 \\
Comfort & 0.043 & 1.411 & 0.003 & 0.939 & 0.348 & 0.588 & \\
Safety & 0.257 & 1.540 & 0.104 & 4.113 & 0.000 & & \\
Reliability & 0.212 & 1.678 & 0.065 & 4.044 & 0.000 & & \\
\hline
\end{tabular}

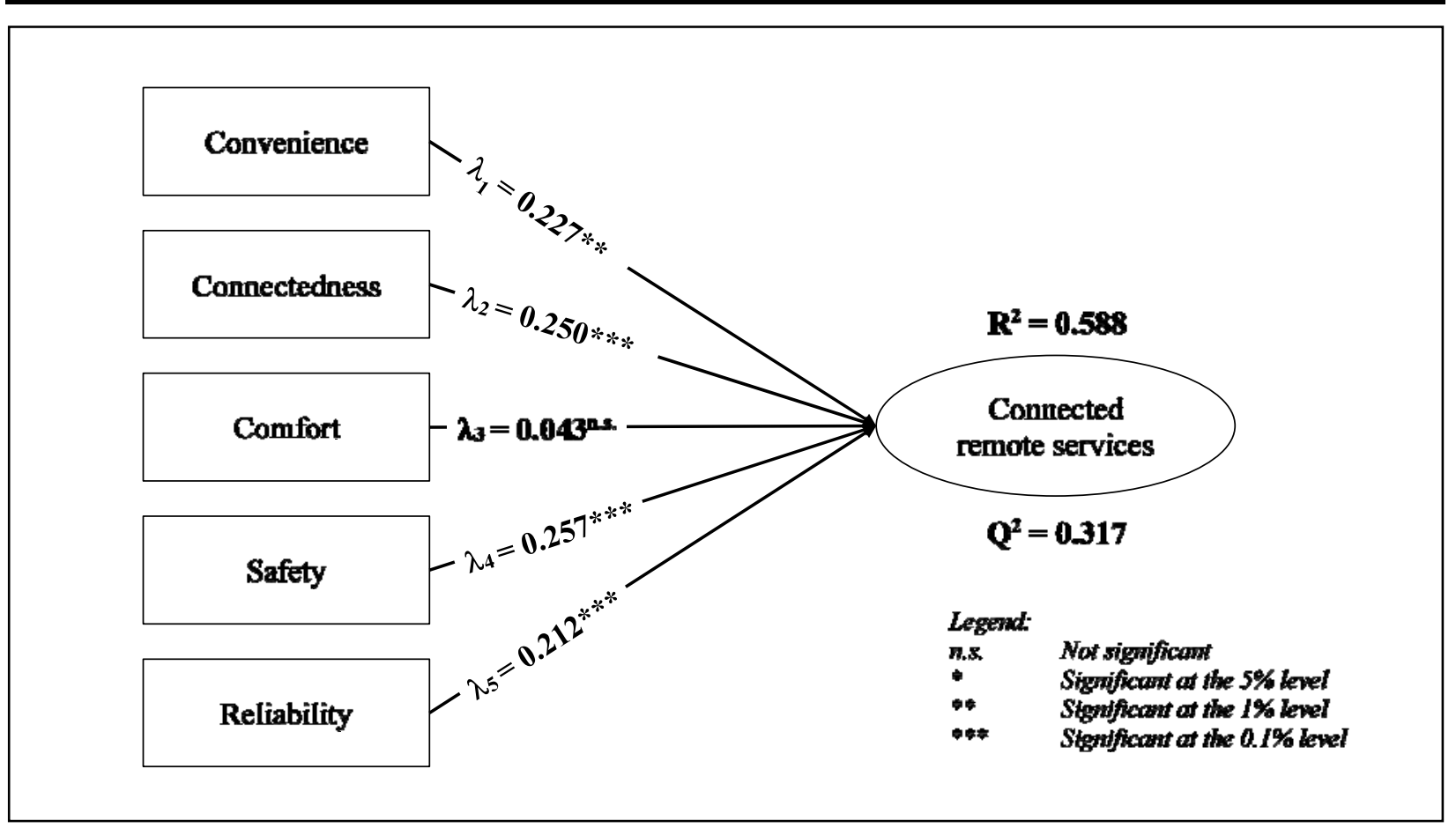

Figure 3. Results of the connected remote services MIMIC model (Author's illustration, based on empirical data).

The evaluation of the CRS MIMIC model questions the assumption that the overall CRS construct consists of five key-factors. All path coefficients, except comfort are significant. For comfort, significance is not given, 
concluding that the concept of comfort may be no key-factor of CRS. Nevertheless, comfort is kept for further considerations, because the qualitative research has shown its relevance. The measured criteria of goodness also show good results, confirming an adequate level of predictive power $\left(\mathrm{R}^{2}=0.588, \mathrm{Q}^{2}=0.317\right)$. The comparison of the path coefficients shows that the four of five key-factors have similar impacts on the overall CRS construct. Safety has the highest contribution to the evaluation of CRS, followed by connectedness, convenience, and reliability. As expected, perceptions on comfort have the lowest impact.

\section{Conclusions}

This empirical study corroborated and further advanced the CRS typology conceptualized by the author of this paper. CRS was conceptualized as a second-order formative construct that is created from five reflective first-order constructs: convenience, connectedness, comfort, safety, and reliability. The empirical results suggest that all five key-factors are a valid way of conceptualizing CRS, however the influence of comfort was shown to be not significant. Despite this result, comfort is maintained as determining concept of CRS based on the findings of the prior conducted qualitative study, which revealed comfort as relevant. Further, the evaluation of discriminant validity shows that comfort is an independent construct. Together the five key-factors cover an acceptable breadth of CRS $\left(\mathrm{R}^{2}=58.8 \%\right)$, whereas safety and connectedness are the most important determinants.

This gives rise to the importance of providing safety-oriented functions of CRS as they are assumed to be beneficiary to users. The importance of safety implies that gaining customer perceptions of feeling secure by using CRS needs to be further considered within the CRS development process. Connectedness as special particularity of CRS was shown to be an important key-factor of CRS and is to be considered as relevant in future research. Although slightly less important, convenience and reliability, remain significant in relation to the overall CRS construct. This unveils the potential of CRS to influence customer perceptions in various directions.

\section{References}

Anderson, J. C., \& Gerbing, D. W. (1991). Predicting the performance of measures in a confirmatory factor analysis with a pretest assessment of their substantive validities. The Journal of Applied Psychology, 76(5), 732-740.

Arndt, S. (2011). Evaluierung der Akzeptanz von Fahrerassistenzsystemen. VS Verlag für Sozialwissenschaften/Springer Fachmedien Wiesbaden GmbH, Wiesbaden.

Berry, L. L., Seiders, K., \& Grewal, D. (2002). Understanding service convenience. Journal of Marketing, (3), 1-17.

Bouwman, H., Vos, H., \& Haaker, T. (Eds.). (2008). Mobile service innovation and business models (1st ed.). Berlin, Heidelberg: Springer-Verlag.

Bracke, S., \& Haller, S. (2011). Advanced reliability analysis of warranty databases (RAW) concept: Contribution to sustainable products and manufacturing. In G. Seliger, M. M. K. Khraisheh, and I. S. Jawahir (Eds.), Advances in sustainable manufacturing. Berlin, Heidelberg: Springer-Verlag.

Confente, I., \& Russo, I. (2015). After-sales service as a driver for word-of-mouth and customer satisfaction: Insights from the automotive industry. International Journal of Management Cases, 17(4), 59-72

Den Hertog, P., Van Der Aa, W., \& De Jong, M. W. (2010). Capabilities for managing service innovation. Journal of Service Management, (4), 490-514.

Diamantopoulos, A., \& Winklhofer, H. M. (2001). Index construction with formative indicators: An alternative to scale development. Journal of Marketing Research, 38(2), 269-277.

Diamantopoulos, A. (2011). Incorporating formative measures into covariance-based structural equation models. MIS Quarterly, $35(2), 335-358$.

Engeln, A., \& Vratil, B. (2008). Fahrkomfort und Fahrgenuss durch den Einsatz von Fahrerassistenzsystemen. In J. Schade and A. Engeln (Eds.), Fortschritte der Verkehrspsychologie, VS Verlag für Sozialwissenschaften/GWV Fachverlage GmbH Wiesbaden, Wiesbaden. 
Gutman, J. (1982). A means-end chain model based on consumer categorization processes. Journal of Marketing, 46, 60-72.

Gutman, J. (1991). Exploring the nature of linkages between consequences and values. Journal of Business Research, (2), 143-148.

Henseler, J. (2017). Bridging design and behavioral research with variance-based structural equation modeling. 46(1), 178-192.

Hess, S. P. (1924). Automobile riding-comfort. Warrendale, PA: SAE International.

Hilke, W., Trippen, L., \& Peiner, W. (1989). Dienstleistungs-marketing: Banken und Versicherungen. Freie Berufe. Handel und Transport. Wiesbaden: Betriebswirtschaftlicher Verlag Dr. Th. Gabler, Wiesbaden.

Hiraoka, C. (2009). Technology acceptance of connected services in the automotive industry. Gabler Verlag/GWV Fachverlage GmbH Wiesbaden, Wiesbaden.

Joewono, T. B., \& Kubota, H. (2006). Safety and security improvement in public transportation based on public perception in developing countries. IATSS Research, 1, 86-100.

Kotler, P., \& Bloom, P. N. (1984). Marketing professional services. Eng-lewood Cliffs, NJ: Prentice-Hall.

Lee, N., Cadogan, J. W., \& Chamberlain, L. (2013). The MIMIC model and formative variables: Problems and solutions. AMS Review: Official Publication of the Academy of Marketing Science, 3(1), 1-17.

Lin, K. Y., \& Lu, H. P. (2015). Predicting mobile social network acceptance based on mobile value and social influence. Internet Research, 25(1), 107-130.

Nitzl, C. (2010). Eine anwenderorientierte Einführung in Partial Least Square (PLS)-Methode. Arbeitspapier Nr. 21, Hamburg.

Nunnally, J. C. (1978). Psychometric theory (2nd ed.). New York: McGraw-Hill.

Spohrer, J., \& Maglio, P. (2008). The emergence of service science: Toward systematic service innovations to accelerate co-creation of value. Production and Operations Management, 17(3), 238-246.

Toivonen, M., \& Tuominen, T. (2009). Emergence of innovations in services. The Service Industries Journal, (7), 887-902.

Vinzi, E., Trinchera, L., \& Amato, S. (2010). PLS path modeling: From foundations to recent developments and open issues for model assessment and improvement. In V. Esposito Vinzi, W. W. Chin, J. Henseler, and H. Wang (Eds.), Handbook of partial least squares: Concepts, methods and applications (pp. 47-82). Berlin: Springer.

Wamba, S. F., \& Akter, S. (2016). Impact of perceived connectivity on intention to use social media: Modelling the moderation effects of perceived risk and security. In Y. K. Dwivedi, M. Mäntymäki, M. N. Ravishankar, M. Janssen, M. Clement and E. L. Slade (Eds.), Social media: The good, the bad, and the ugly. Switzerland: Springer.

Wünderlich, N. V., Schumann, J. H., Wangenheim, F. V., \& Holzmüller, H. H. (2007). Ferngesteuerte Dienstleistungen. Betriebswirtschaftliche Spezifika, Terminologie und Herausforderungen für das Management. In D. Holtbrügge, F. Wangenheim, and H. H. Holzmüller (Eds.), Remote services (p. 1). DUV Deutscher Universitäts-Verlag. 